\title{
RATIONAL DEVELOPMENT OF NEW COOLING WATER CHEMICAL TREATMENT PROGRAMS FOR SCALE AND MICROBIAL CONTROL
}

\author{
Kostas D. Demadis, Bo Yang, Paul R. Young, Dmitri L. Kouznetsov, and \\ Douglas G. Kelley \\ Nalco Chemical Company \\ Global Water Research \\ One Nalco Center \\ Naperville, IL 60563-1 198
}

\section{INTRODUCTION}

Crystal growth is part of a more extensive problem in supersaturated cooling waters known as scale formation. Scale usually refers to an intimate mixture of a multitude of sparingly soluble mineral salts. Depending on the $\mathrm{pH}$, temperature and water chemistry, these salts include but are not limited to calcium carbonate, calcium phosphate, silica, silicate salts, calcium sulfate, corrosion products (iron (hydr)oxides) etc. Calcium carbonate is the predominant component of the hard and tenacious scale deposited from natural waters, especially in processes involving heat transfer. The main focus of this paper is on two major system stresses, high $\mathrm{Ca}^{2+}$ and oxidizing biocides, and under conditions common in Heating, Ventilation and Air Conditioning (HVAC) systems.

The chief factor that promotes calcium carbonate scale formation is concentration of dissolved solids by repeated partial evaporation of the water. ${ }^{1,2}$ Therefore, a certain water that has no scale tendency will eventually become scale-forming when concentrated $\mathrm{n}$ times, where $n=2,3,4$ and even higher. The number $n$ is defined as cycles of concentration (COC's). Economic considerations to minimize water use require low blowdown and increased COC's.

The severity of the scaling tendency of a certain water is related to the saturation index (SI), defined as follows:

$$
S I=\frac{\left[\mathrm{Ca}^{2+}\right] \cdot\left[\mathrm{Ca}_{3}^{2-}\right]}{\mathrm{KspCaCO}}
$$


$\left[\mathrm{Ca}^{2+}\right]$ and $\left[\mathrm{CO}_{3}^{2-}\right]$ are the activities of the corresponding free ions and $\mathrm{K}_{\mathrm{Sp}} \mathrm{CaCO}_{3}$ is the conditional solubility product for $\mathrm{CaCO}_{3}$.

Cooling water represents the single largest portion of industrial water use. Hot processes, from air-conditioning to catalytic hydrocarbon cracking, have to be cooled. Water is the most abundant and cheapest cooling medium. The water is pumped across a metal heat exchanger in contact with the hot process. The water heats up upon cooling of the process and has to be cooled in order to be re-used for cooling purposes. This cooling of the water is usually achieved by evaporative cooling in a system known as a cooling tower. A schematic representation of a typical cooling tower set-up is shown in Figure 1.

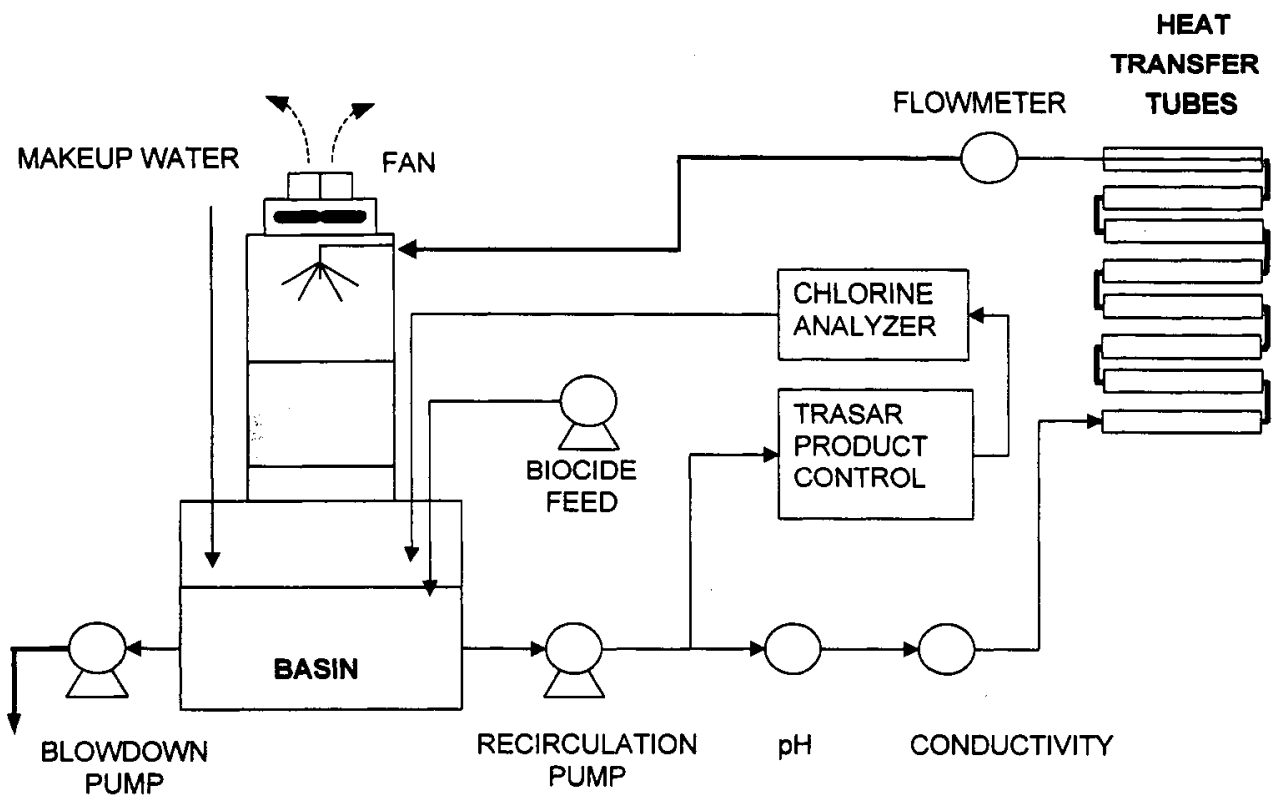

Figure 1. Schematic drawing showing the basic components of a cooling tower.

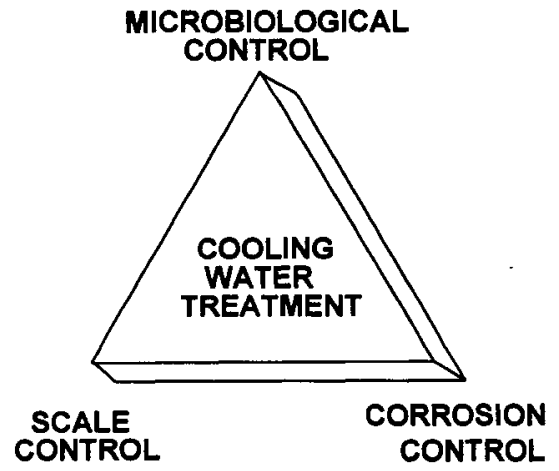

Figure 2. The water treatment triangle model. 
Evaporation causes an increase in dissolved solids concentration. Moreover, carbon dioxide is stripped away and the result is a $\mathrm{pH}$ increase. As a result, water becomes highly supersaturated with respect to mineral salts. At this highly metastable situation, alkaline earth salts (especially calcium carbonate) precipitate. This may lead to massive deposit of the scale onto critical surfaces. The metal surfaces (heat exchangers) are usually very critical pieces of equipment and great care has to be taken so scale deposits on them can be avoided. Further information on the operation of cooling towers from an engineering perspective can be found in numerous specialized reports. ${ }^{2-7}$

Calcium carbonate is an especially problematic scale because it possesses "inverse solubility", i.e. it becomes less soluble at higher temperatures. Because of that, it tends to accumulate and deposit onto hot surfaces, where it is least desired. $\mathrm{CaCO}_{3}$ tends to form tenacious scale that strongly adheres to heat transfer surfaces. It can be cleaned by acid, but this involves a corrosive procedure and results in operations downtime.

Mineral scale deposits are not the only issues that adversely affect the proper operation of a cooling tower and, by extension, of the hot process. Corrosion and microbiological growth are equally important factors that have to be controlled along with scale formation. These are the three most important challenges in cooling water treatment (Figure 2).Details on corrosion and bacterial growth are beyond the scope of this paper and will be subjects of future reports.

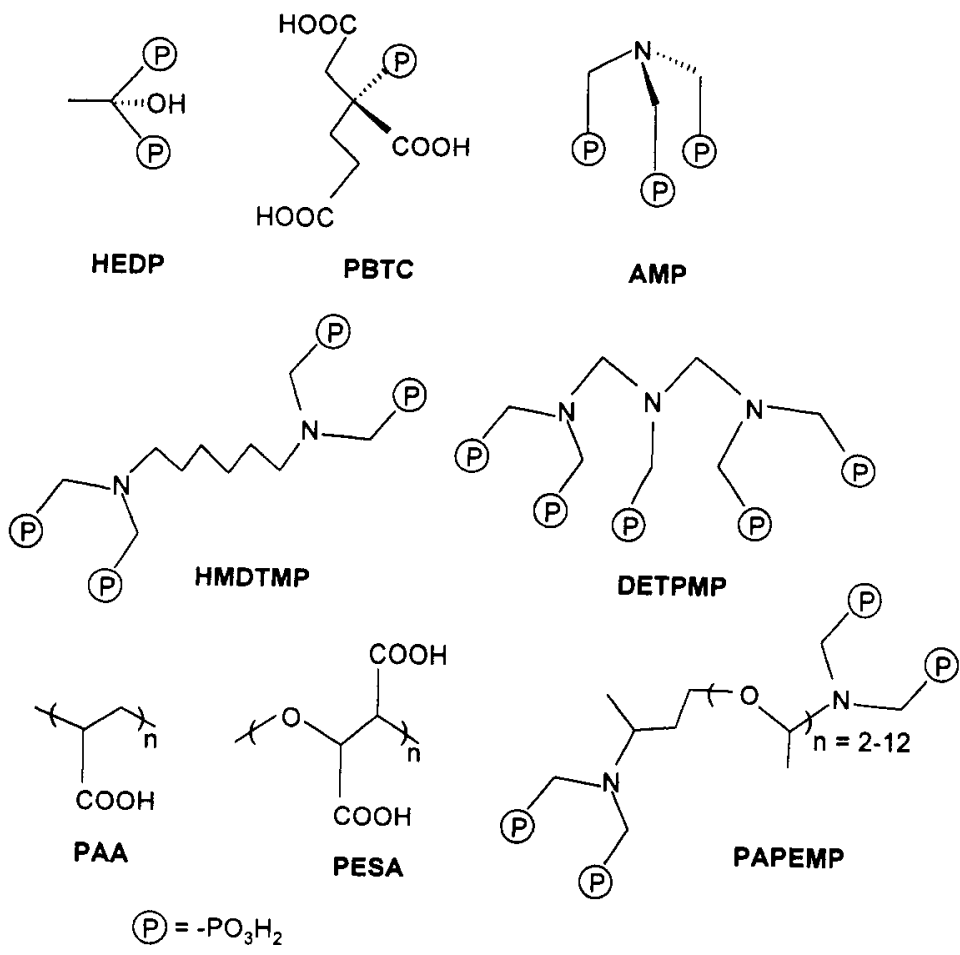

Figure 3. Schematic molecular structures of some representative calcium carbonate inhibitors. The symbol abbreviations are as follows: HEDP, 1-hydroxyethylidene-1,1-diphosphonic acid; PBTC, 2-phosphonobutane-1,2,4-tricarboxylic acid; HMDTMP, hexamethylene-N,N',N',N'-diamine tetramethylenephosphonic acid; DETMP, diethylene triaminepenta (methylenephosphonic acid); PAA, polyacrylic acid; PESA, polyepoxysuccinic acid; PAPEMP, polyaminopoly-ethylenephosphonic acid. 
There are four basic approaches for calcium carbonate scale control: (a) use of acid; (b) use of sequestrants; (c) maintain low cycles of concentration; and (d) use of scale inhibitors. Use of acid is an effective way to prevent calcium carbonate formation by maintaining a low $\mathrm{pH}$. However, it raises concerns due to its hazardous nature and the potential of accelerating metal corrosion. The use of sequestering agents is too expensive for recirculating water applications. Maintaining low cycles of concentration leads to rather costly water waste. Scale inhibitor use is the most widely accepted practice and involves the addition of minute amounts of organic compounds (usually at the ppm level) in the recirculating water. These compounds usually are phosphonates and carboxylates, and can be monomeric or polymeric. Representative schematic structures are shown in Figure 3.

These molecules function at threshold levels, since the Ca:inhibitor concentration ratio is extremely high. It is believed that they perform "threshold inhibition" by a surface adsorption mechanism involving Langmuir adsorption. Adsorption onto the $\mathrm{CaCO}_{3}$ surface causes inhibition (or delay) of crystal growth at the very early stages. Several studies have been reported on this adsorption chemistry for $\mathrm{CaCO}_{3}$ and other scales.

In water treatment programs, other components are often formulated with the scale inhibitors. For example, yellow metal corrosion inhibitors, dispersant polymers and tracers can be parts of the same treatment, whereas biocides for microbial control, such as chlorine or bromine, are fed separately.

\section{Mechanism of Scale Formation}

As noted above, scale formation is a complex combination of a number of processes. ${ }^{8-11}$ Initial electrostatic interaction of dissolved anions and cations is the genesis of ion pairs that sequentially act as "building blocks". They later assemble to form larger aggregates. Externally added molecules can interfere with thisassembly process and disrupt subsequent formation of larger particles. In the absence of such molecules, generation of these larger particles is inevitable.

Supersaturation is the driving force for the enlargement and growth of these aggregates to a "critical size". At that time, nucleation of a solid state particle occurs. Contrary to the smaller-size aggregates, these larger particles do not easily re-dissolve, and therefore serve as growth surfaces for crystal growth. The above process is called homogenous nucleation and refers to particle formation in the bulk of the solution. On the other hand, heterogenous nucleation relates to generation of nuclei onto a surface (e.g., a metal surface in contact with the supersaturated water).

Following the nucleation event (either homogenous or heterogeneous), several deposit growth mechanisms can occur, which involve one or more of the following: (a) crystal growth, that is cation-anion incorporation (e.g., $\mathrm{Ca}^{2+}$ and $\mathrm{CO}_{3}{ }^{2-}$ ) directly along certain crystallographic planes of a crystallite;, (b) particle agglomeration; (c) deposit on "hot" metal surfaces; (d) biofilm-induced scale growth.

\section{EXPERIMENTAL SECTION}

\section{Crystal Growth and Structure of a Ca-AMP Precipitate}

AMP (40\% solution in water) and $\mathrm{CaC} 12.2 \mathrm{H} 2 \mathrm{O}$ are commercial samples. Single crystals of Ca-AMP were obtained in the following way. AMP $(5.0 \mathrm{~mL}, 0.5 \mathrm{M}$ solution in deionized water) was acidified with a $10 \% \mathrm{HCl}$ solution until the $\mathrm{pH}$ was 1.5 . 
Subsequently, a solution of $\mathrm{CaCl}_{2} \cdot 2 \mathrm{H}_{2} \mathrm{O}(5.0 \mathrm{~mL}, 0.5 \mathrm{M}$ in deionized water $)$ was added under vigorous stirring, while the $\mathrm{pH}$ was constantly monitored. The $\mathrm{pH}$ dropped and was re-adjusted to 1.5 by addition of $0.1 \mathrm{~N} \mathrm{NaOH}$ solution. The beaker was covered and set aside. During the crystallization process, large $(0.25 \times 0.20 \times 0.10 \mathrm{~mm})$, transparent crystals (rectangular plates) formed and were isolated by filtration. They were washed with deionized water and air-dried. The crystals were stored in an air-tight container to minimize exposure to air and humidity.

Several regularly shaped, colorless, transparent crystals were selected, and submitted for single crystal X-ray data collection. Data were collected at -100 "C using a cold stream of evaporated liquid $\mathrm{N}_{2}$ to minimize thermal motion. Standard crystallographic methods (direct methods) were used to initially locate the heavier atoms in the structure. The remaining non-hydrogen atoms were located in subsequent difference Fourier maps. Empirical absorption corrections were applied with SADABS. The ORTEP plotting program was used to computer-generate the structure. ${ }^{12}$ All atoms were refined anisotropically. Hydrogen atoms were located in the difference Fourier map and refined as well. All computations were performed by using the NRCVAX suite of programs. ${ }^{13}$ Atomic scattering factors were taken from a standard source ${ }^{14}$ and corrected for anomalous dispersion.

\section{Turbidity Test (Ca Tolerance)}

Inhibitor tolerance towards calcium was measured by turbidity monitoring. The test set-up used a constant temperature water bath $\left(130 \pm 0.5 \mathrm{~F}, 54.4^{\circ} \mathrm{C}\right)$, two precision syringe pumps (for the inhibitor and $0.1 \mathrm{~N} \mathrm{NaOH}$ solution), and a Brinkman PC 700 Colorimeter with $420 \mathrm{~nm}$ filter (for transmittance measurements).

Four hundred $\mathrm{mL}$ of a $1000 \mathrm{ppm}$ solution of $\mathrm{CaCl}_{2} \cdot 2 \mathrm{H}_{2} \mathrm{O}$ (as $\mathrm{CaCO}_{3}$ ) in deionized water was placed in a $700 \mathrm{ml}$ glass beaker. The beaker was covered with a rubber piece holding the turbidity and $\mathrm{pH}$ probes, and a thermometer was placed in the water bath. Appropriate time was allowed for temperature and $\mathrm{pH}$ to equilibrate. Then, a $2000 \mathrm{ppm}$ (as actives) solution of inhibitor was pumped in at a rate of $0.25 \mathrm{ml} / \mathrm{min}$. A constant $\mathrm{pH}$ of $9 \pm$ 0.05 was maintained by addition of caustic and controlled by a PHCN-37 controller (from Omega Engineering). The transmittance response and maintained $\mathrm{pH}$ value were continuously recorded using a PC computer with a PCL-812 PG data acquisition board.

When the concentration of the inhibitor in the beaker exceeded a certain limit, the solution became turbid, which was detected by a steep decrease in light transmittance. Data acquisition was continued for several minutes to precisely determine the inflection point. Calcium tolerance of an inhibitor was determined as the ratio of ppm inhibitor to $\mathrm{ppm} \mathrm{Ca}^{2+}$ as $\mathrm{CaCO}_{3}$ in the solution at the inflection point adjusted to $1000 \mathrm{ppm} \mathrm{Ca}^{2+}\left(\right.$ as $\left.\mathrm{CaCO}_{3}\right)$. Reproducibility of results was within $10 \%$ error.

\section{$\mathrm{CaCO}_{3}$ Solubility Stress Tests}

pH Static Test. In this test, the desired amounts of $\mathrm{CaCl}_{2} \cdot 2 \mathrm{H}_{2} \mathrm{O}$ and $\mathrm{MgSO}_{4} \cdot 7 \mathrm{H}_{2} \mathrm{O}$ (from a 40,000 ppm stock solution) were first dissolved into a volumetric flask containing $60 \%$ of the final volume de-ionized water. Next, the inhibitor or inhibitor formulation was added to the flask. Another $30 \%$ of the final volume of de-ionized water was added into the flask and mixed well with the original solution. Then the desired amount of $\mathrm{NaHCO}_{3}$ (from a 40,000 ppm stock solution) was added into the solution. Finally, de-ionized water was added to the flask until the total final volume is reached. Depending on the test analysis 
requirements, the final volume of the test solution was between $100-500 \mathrm{ml}$. The solution was then transferred to an Erlenmeyer flask. The flask was covered and put in a water bath set at the specified temperature. The solution inside the flask was under constant stirring with a magnetic stirring bar. $\mathrm{pH} 9.0$ was maintained by addition $0.1 \mathrm{~N} \mathrm{NaOH}$ via an autotitrator. After a chosen time period $(2-3 \mathrm{hr})$, the flask was removed from the water bath, and $0.45 \mu$ filtered solution samples were taken immediately. Analyzing these samples yielded the soluble concentration of $\mathrm{Ca}^{2+}$. The remaining solution was covered and stored unstirred at room temperature. Twenty-four hours after the $\mathrm{pH}$ was first raised to 9.0, unfiltered solution samples were taken from just below the surface. The analytical results of these samples yielded the dispersed $\mathrm{Ca}^{2+}$ concentration.

Aeration Test. In this method, the experimental procedure was similar to the one described above as "pH Static test", except that aeration was used to raise the solution $\mathrm{pH}$. This was achieved with a constant flow of air through a sintered glass diffuser. The solution samples were taken and analyzed identically as in the $\mathrm{pH}$ Static test.

It should be pointed out that the aeration test appears to be a better simulation of a commercial open recirculating cooling water system than the $\mathrm{pH}$ static test. Just as such systems, the solution $\mathrm{pH}$ depends on soluble M-alkalinity and other solution species. In addition, the amount of M-alkalinity added into each test solution will be well defined, in contrast to the $\mathrm{pH}$ static test where the amount of $\mathrm{NaOH}$ added depends on the performance of the inhibitor used. The worse an inhibitor performs, the more $\mathrm{NaOH}$ is added to the solution.

\section{Pilot Cooling Tower (PCT) Tests}

Pilot cooling tower (PCT, Figure 1) tests were run as described by Nass \& Reed and Fulks and Yeoman. ${ }^{15,16}$ Heat exchange tubes were 304 stainless steel, admiralty brass, copper, or carbon steel (mild steel). Most tests had two tubes of each metal, or three each SS and MS with no copper. Tubes were heated with electrical resistance heaters of 200 or $400 \mathrm{~W}$ power. Because the Heating, Ventilation and Air Conditioning (HVAC) systems usually use mild steel pipes to transport water, and use copper or brass as the prefered heat exchanger metallurgy, the mild steel tubes were not heated to better simulate this situation. Water flow was about $9 \mathrm{~L} / \mathrm{min}$, giving a velocity of $1 \mathrm{~m} / \mathrm{s}$. The tubes' surface temperatures are estimated to be about $5-8^{\circ} \mathrm{C}$ higher than the water temperature.

Parameters varied in this work were temperature, biocide, and treatment level of each component. Basin temperatures were controlled at either 27 or $32 \pm 1{ }^{\circ} \mathrm{C}$, with a $\Delta \mathrm{T}$ of 2-3 ${ }^{\circ} \mathrm{C}$. Formulations containing various amounts of scale inhibitors (AMP, PBTC, HEDP, PAA) and dispersant polymer were prepared. Many of these contained a tracer and/or a triazole corrosion inhibitor. Some formulations included a surfactant as a dispersant. A conductivity monitor controlled a blowdown pump, initiating blowdown whenever the conductivity exceeded the setpoint. After several days at a given conductivity with no scale observed on the tubes, the conductivity setpoint was increased by $100-300 \mu$ mhos. Daily chemical water analyses of the recirculating tower water were performed.

Deposit formation on heated surfaces is monitored during each test visually and with a DATS fouling monitor manufactured by Bridger Scientific Co. This unit determines the resistance to heat transfer (HTR) across a precisely controlled heated surface. By measuring water temperature and heater block temperature, while controlling heat flux and water velocity, the DATS computer calculates a relative HTR every 30 seconds. When HTR increases, a deposit of some type has formed an insulating layer on the surface. 
Commercial corrosion monitors, Corraters from Rohrback/Cosaco Co. provided continuous measurements of corrosion rates. These agreed well with visual and gravimetric data. Most formulations had a fluorescent tracer for better program control. For products with fluorescent tracers, an on-line fluorometer (TRASAR ${ }^{\circledR}$ technology) was used to measure and maintain product dosage. ${ }^{17}$

Other products were fed via calibrated syringe pumps activated whenever blowdown was turned on. These syringe pumps were set to deliver the calculated volume of product per liter of blowdown, given the known (usually measured independently) blowdown pump rate. A computer data acquisition system recorded the output from numerous on-line instruments. Conductivity, $\mathrm{pH}$, basin and return temperatures, and outputs from fluorometer, Corrater and DATS were stored every 30 minutes. Oxidizing biocides were fed via a syringe pump at a constant rate, but the rate was occasionally increased or decreased in order to maintain the target residual. Most tests used either stabilized bromine at $0.2-0.8 \mathrm{ppm}$ (as total $\mathrm{Cl}_{2}$ ) or stabilized chlorine at 1-5 ppm (as total $\mathrm{Cl}_{2}$ ). Three tests used bleach at $0.1-0.5 \mathrm{ppm}$ total $\mathrm{Cl}_{2}$.

\section{RESULTS AND DISCUSSION}

\section{Effect of $\mathrm{Ca}^{2+}$ Stress}

Effect of High $\mathrm{Ca}^{2+}$ on Inhibitors. Calcium tolerance is defined as the ability of a certain chemical compound to remain soluble in the presence of calcium ions. Tolerance usually decreases as $\mathrm{pH}$ increases. This is because at higher $\mathrm{pH}$ 's the degree of deprotonation of inhibitors (usually phosphonates or carboxylates) is higher.

Calcium tolerance becomes very critical as COC's increase. An efficient inhibitor must interact strongly with $\mathrm{Ca}^{2+}$, but must be sufficiently soluble to remain in the system. A Cainhibitor precipitate is a scale by itself. Such precipitates have adverse effects on the whole treatment program because: (a)the system is depleted of inhibitor, resulting in poor scale control and higher chemical costs; (b) such Ca-inhibitor scales usually have the same inverse solubility features commonly observed with scales; (c) they impede heat transfer.

Ca-inhibitor salt precipitation is well known for phosphonate as well as carboxylatebased inhibitors. Results obtained for AMP, PBTC, and HEDP phosphonates are shown in Figure 4. The above inhibitors can be rated according to their $\mathrm{Ca}$ tolerance in descending

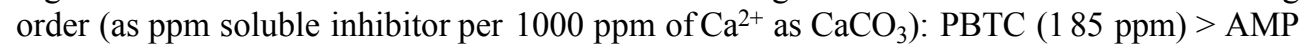
$(12 \mathrm{ppm})>\operatorname{HEDP}(8 \mathrm{ppm})$.

The presence of a polymeric dispersant has a profound effect on Ca-inhibitor salt precipitation. In one of the series, $20 \mathrm{ppm}$ of Dispersant $\mathrm{A}$ was added to the calcium solution before HEDP addition started. As shown in Figure 5, the dispersant alleviated CaHEDP salt precipitation and effectively increased its solubility $\sim 200 \%$. Finally, turbidity was noted at 19 ppm HEDP.

Crystal and Molecular Structure of a Ca-AMP Complex. A better understanding of Ca-inhibitor interactions in the solid state may give insights to the inhibitory action of methylenephosphonate inhibitors. Thus, a Ca-AMP crystalline precipitate was studied by single crystal X-ray diffraction. Two representative views of different portions of the molecular structure, as well as salient metric features, are shown in Figure 6. There are no discrete molecular units of the Ca-AMP complex. Instead, the AMP methylenephosphonate "arms" participate in an intricate network of $\mathrm{Ca}-\mathrm{O}$ bonds and hydrogen bonds. 
The result is an intricate polymeric three-dimensional structure characterized by multiple bridging of the AMP molecules.

There are four molecules of Ca-AMP per unit cell. The Ca:AMP molar ratio is 1:1 and is consistent with the absence of any other ions in the crystal lattice. The overall negative charge on the AMP is " -2 " (" -3 " from the phosphonate groups and " +1 " from the protonated N). The crystal lattice of Ca-AMP is hydrated and contains overall $3^{1 / 2}$ water molecules per one molecule of AMP. Water molecules of crystallization serve as "space fillers" and also participate in extensive hydrogen bonding superstructures, acting as bridges. Detailed crystallographic data on the Ca-AMP structure are available from the authors (KDD) upon request.

Coordination Environments: $\mathrm{Ca}$ Atom. The coordination environment of the $\mathrm{Ca}$ atom is shown in Figure 6. Ca is pseudo-octahedral, surrounded by five phosphonate oxygens and a water molecule. $\mathrm{Ca}-\mathrm{O}(\mathrm{P})$ bond lengths range from 2.2924(14) to 2.3356(14) $\AA$ The $\mathrm{Ca}-\mathrm{O}(\mathrm{H} 2 \mathrm{O})$ bond is $2.3693(17) \AA$ long, somewhat longer than $\mathrm{Ca}-\mathrm{O}(\mathrm{P})$ bonds. The $\mathrm{Ca}$ atom is situated in a slightly distorted octahedral environment, as judged by the O-Ca-O angles. Average $\mathrm{Ca}-\mathrm{O}(\mathrm{P})$ bond lengths are comparable to similar bonds found in the literature.

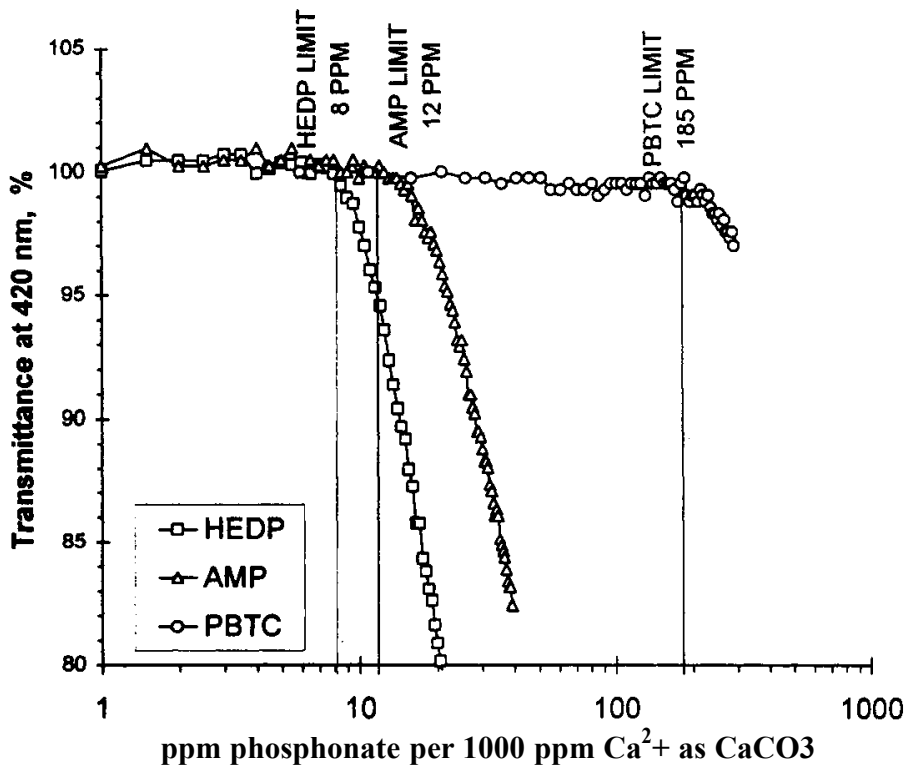

Figure 4. Precipitation of Ca-Inhibitor complexes as monitored by turbidity measurements. Results are presented as ppm phosphonate added to a $1000 \mathrm{ppm} \mathrm{Ca}^{2+}$ solution, at $130^{\circ} \mathrm{F}$ and $\mathrm{pH} 9$.

$\mathbf{P O}_{3}$ Groups. All three phosphonate groups in AMP are mono-deprotonated. This separates the $\mathrm{P}-\mathrm{O}$ bonds into two groups: $\mathrm{P}-\mathrm{OH}$ (protonated) and $\mathrm{P}^{-} \mathrm{O}^{-}$(deprotonated). There is one $\mathrm{P}-\mathrm{OH}$ group and two $\mathrm{P}-\mathrm{O}$ groups per phosphonate moiety. The two $\mathrm{P}-\mathrm{O}$ 


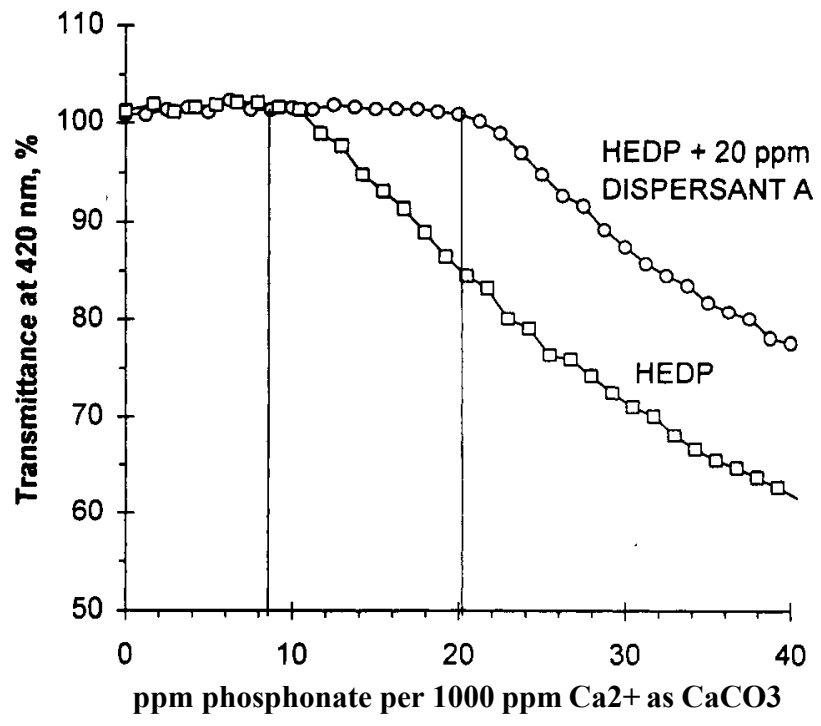

Figure 5. Effect of Dispersant A on the precipitation of Ca-HEDP as monitored by turbidity measurements. Results are presented as ppm phosphonate added to a $1000 \mathrm{ppm} \mathrm{Ca}^{2+}$ solution, at $130^{\circ} \mathrm{F}$ and $\mathrm{pH} 9$.
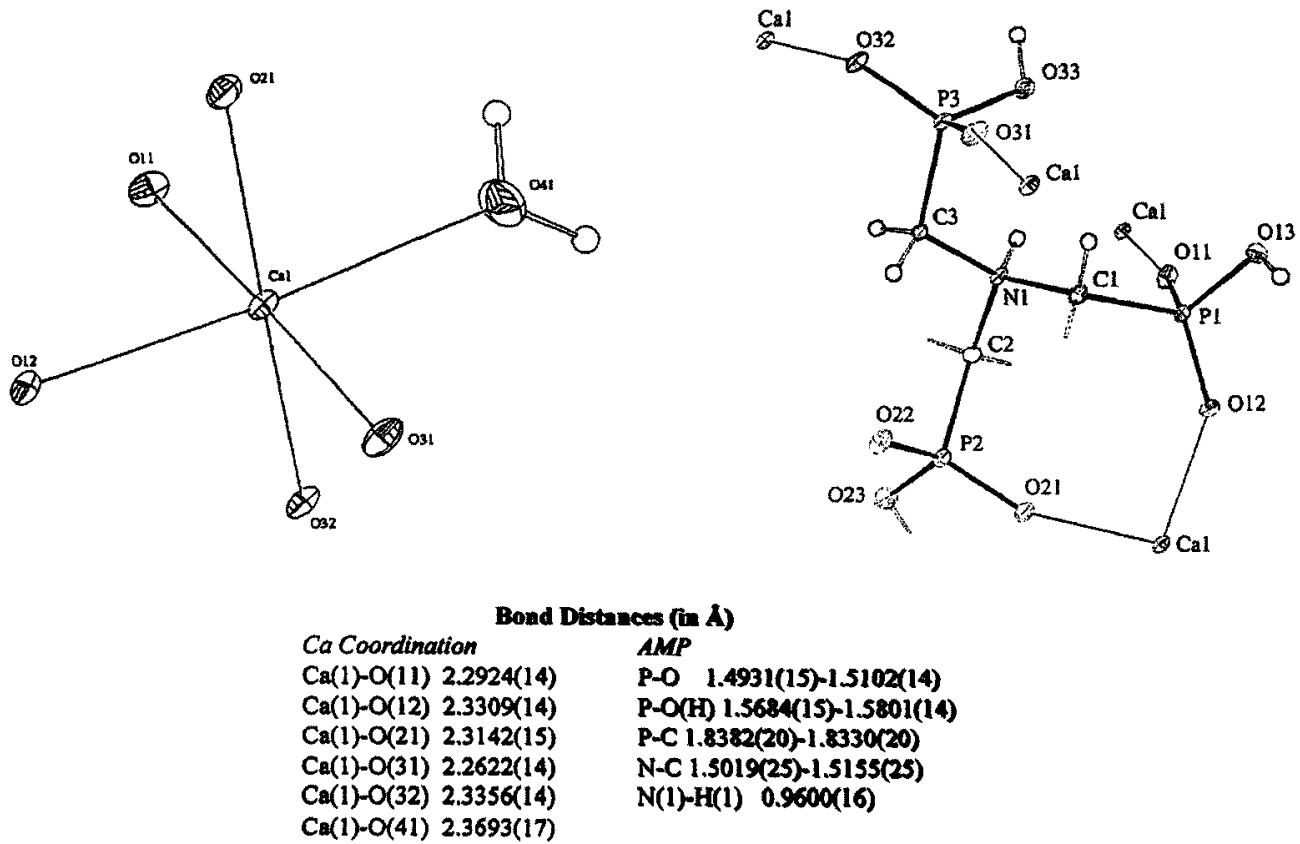

Figure 6. Molecular structure of Ca-AMP and important metric features. 
groups share a single negative charge. Deprotonated P-O bond lengths are in the region 1.4931(15)-1.5102(14) $\AA$ On the other hand, protonated P-O bond lengths are slightly longer, in the region 1.5684(15)-1.5801(14) $\AA$ It is worth noting that only the deprotonated $\mathrm{P}-\mathrm{O}$ groups coordinate to the $\mathrm{Ca}$ atoms.

P-C bond lengths fall in the normal range (1.8-1.9 $\AA$ ) and are 1.8382(20) $\AA, 1.8347(20) \AA$ and $1.8330(20) \AA$

Literature Cases and Comparisons. There is a plethora of crystal and molecular structures of mono-phosphinates ${ }^{18}$ and mono-phosphonates ${ }^{19,20}$ in the crystallographic literature. In addition, an extensive number of structures of bis phosphonates ${ }^{21,22,23}$ exist, but only a limited number of reports on $\mathrm{Ca}^{2+}$-bis -phosphonate complexes. ${ }^{24,25,26}$ Furthermore, ab initio studies on relevant organophosphorous compounds and their $\mathrm{Ca}$ complexes have been carried out. ${ }^{27}$ Substantial interest has been focused on 1,1-bis phosphonates (or gem- bis-phosphonates). ${ }^{28}$ On the other hand, two neighboring (geminal) phosphonate groups are not a necessary requirement for good scale inhibition. AMP and PBTC are both excellent $\mathrm{CaCO}_{3}$ inhibitors. A brief review of representative literature cases relevant to this study follows.

Uchtman described the crystal structure of a Ca-HEDP complex. ${ }^{24} \mathrm{Ca}$ is octacoordinate bound by two $\mathrm{H}_{2} \mathrm{O}$ molecules, two phosphonate oxygens, and the protonated hydroxyl group. The structure is polymeric. $\mathrm{Ca}-\mathrm{O}\left(\mathrm{PO}_{3}\right)$ bond lengths are 2.352(4) and 2.420(3) $\AA$, whereas the $\mathrm{Ca}-\mathrm{O}(\mathrm{H})$ bond is much longer, at 2.608(3) $\AA$ In a similar Rb-HEDP complex $\mathrm{Rb}-\mathrm{O}\left(\mathrm{PO}_{3}\right)$ bond lengths are 2.949(3) $\AA$ and 2.952(3) $\AA$ whereas the $\mathrm{Rb}-\mathrm{O}(\mathrm{H})$ bond is much longer, at 3.078(3) $\AA .29$

Nardelli et al. described the crystal structure of calcium dichloro-methylene diphosphonate. ${ }^{25}$ Phosphonate groups are monodeprotonated, and there is extensive hydrogen bonding. $\mathrm{Ca}$ is heptacoordinate and is bonded to 5 water molecules and two phosphonate O's from the same chelating dichloro-methylene diphosphonate. Ca-O(P) bond lengths are 2.362(3) $\AA$, and $\mathrm{Ca}-\mathrm{O}\left(\mathrm{H}^{2} 0\right)$ bond lengths are in the region 2.418(4)2.428(4) ^.

The Ca salt of $N$-(phosphonomethyl)glycine (glyphosate) was studied by Raymond et al. ${ }^{19}$ The structure is polymeric. The $\mathrm{Ca}$ is seven-coordinate with four oxygen atoms from three different glyphosate groups, one carboxylate oxygen from another glyphosate and two water oxygens. Each glyphosate is in turn bonded to four different $\mathrm{Ca}$ atoms through both the phosphonate and carboxylate groups. The $\mathrm{N}$ atom is protonated and therefore does not participate in any $\mathrm{Ca}$ binding. One phosphonate group from the glyphosate ligand acts as a bridge between two $\mathrm{Ca}$ centers and brings them to a distance of $3.93 \AA$ apart. $\mathrm{Ca}-\mathrm{O}(\mathrm{P})$ bond lengths vary. Ca-O(bridging) is 2.51 1(1) $\AA$ long, much longer than a "normal" Ca-O bond of $2.368(1) \AA$ in the same molecule.

Mathew et al. reported the crystal structure and spectroscopic properties of a Ca complex with a novel bis phosphonate, glutarylbis(phosphonate), G1BP. ${ }^{26}$ This is a phosphonate that has an acyl group next to the phosphonate group. The structure can be described in terms of a covalently pillared layer-type arrangement of neutral Ca-GIBP-Ca units along the b-axis. Each oxygen atom of the PO3 group is bonded to a different $\mathrm{Ca}$ ion, and each $\mathrm{Ca}$ in turn is, linked to three $\mathrm{PO}_{3}$ groups. $\mathrm{Ca}-\mathrm{O}(\mathrm{P})$ bond lengths are $\sim 2.38 \AA$

Complex formation equilibria studies of amino phosphonates exist. ${ }^{30-33}$ More specifically, Sawada et al. reported studies on Ca-AMP complex formation. ${ }^{34}$ They suggested that AMP binds to alkaline earth metal ions in a tetradentate fashion (presumably at high pH's), through three phosphoryl O's (originating from three different $\mathrm{PO}_{3}$ 's) and the central $\mathrm{N}$ atom. As the $\mathrm{pH}$ decreases, they propose that the tetradentate 
AMP becomes tridentate because the central $\mathrm{N}$ is protonated, and gets "pushed-back," away from the $\mathrm{Ca}$ center. The proposed structure was said to be consistent with the one proposed previously, which was based on infrared spectroscopy. ${ }^{35}$

Calcium Carbonate Scale Inhibition: Screening Methodology. Soluble and dispersed $\mathrm{Ca}$, obtained by the $\mathrm{pH}$ Static test method as a function of PBTC concentration, are shown in Figure 7. The corresponding results obtained by the aeration method are shown in Figure

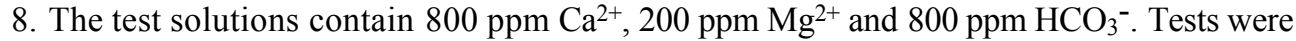
carried out at $110{ }^{\circ} \mathrm{F}$. Results obtained from both methods show that in general, as the PBTC concentration increases beyond some threshold value ( $>3 \mathrm{ppm}$ based on the aeration method), the soluble and dispersed $\mathrm{Ca}$ concentrations increase as well. The increase is rapid up to $10 \mathrm{ppm}$ PBTC, then begins to level off, finally reaching a plateau at $\geq 40 \mathrm{ppm}$ PBTC.

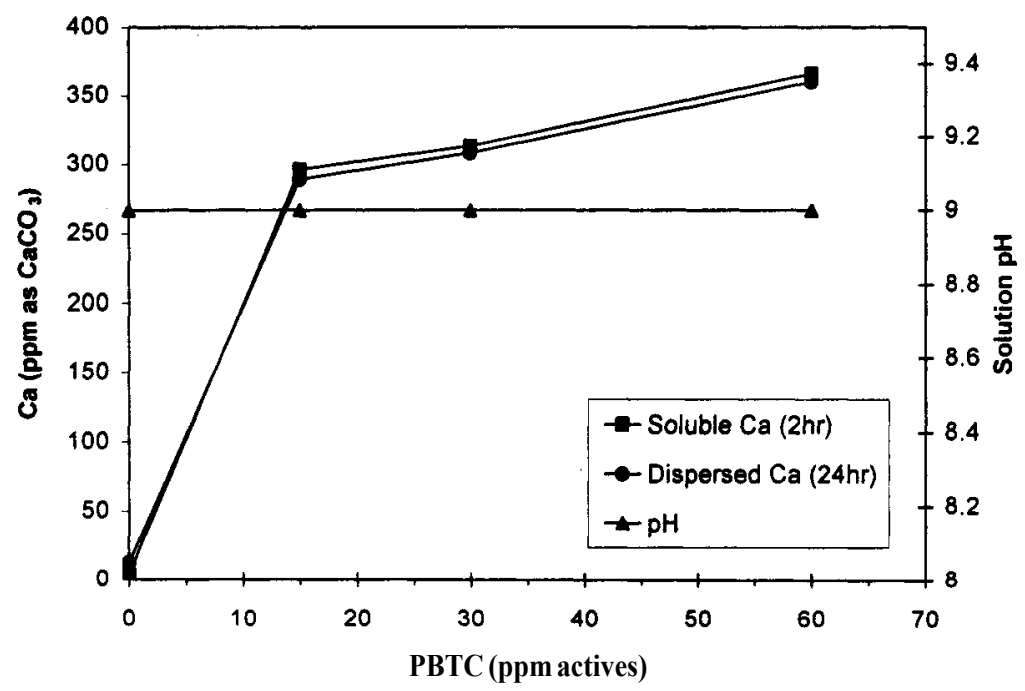

Figure 7. $\mathrm{CaCO}_{3}$ inhibition in the presence of various dosages of PBTC. Results were obtained with the $\mathrm{pH}$ static test. Conditions were: $800 \mathrm{Ca}, 200 \mathrm{Mg}, 800 \mathrm{NaHCO}_{3}$ (all in ppm as $\mathrm{CaCO}_{3}$ ), $\mathrm{pH}$ 9, at $110{ }^{\circ} \mathrm{F}$.

The results also show that the aeration method yielded a much higher soluble/dispersed $\mathrm{Ca}$ than the ones obtained by the $\mathrm{pH}$ static method. This can be explained by the potential presence of local high $\mathrm{pH}$ regions as the caustic is added to the Ca solution, which would lead to pronounced precipitation of $\mathrm{CaCO}_{3}$ in such regions. In addition, in the $\mathrm{pH}$ static test as $\mathrm{CaCO}_{3}$ precipitates more base is added to maintain the $\mathrm{pH}$. This increases the alkalinity, forcing additional precipitation.

Inhibitor Performance. It is rather difficult to address all factors and variables affecting $\mathrm{CaCO}_{3}$ scale inhibition at the same time in a "beaker" test. Nevertheless, a simple screening test can provide useful performance and kinetic information on inhibition of $\mathrm{CaCO}_{3}$ scale. The aeration method was used to study the inhibiting properties of PBTC, HEDP, AMP, polyacrylate $(\mathrm{MW}=5000)$, dispersant $\mathrm{A}(5-20 \mathrm{ppm}$ actives $)$ in solutions containing 600 


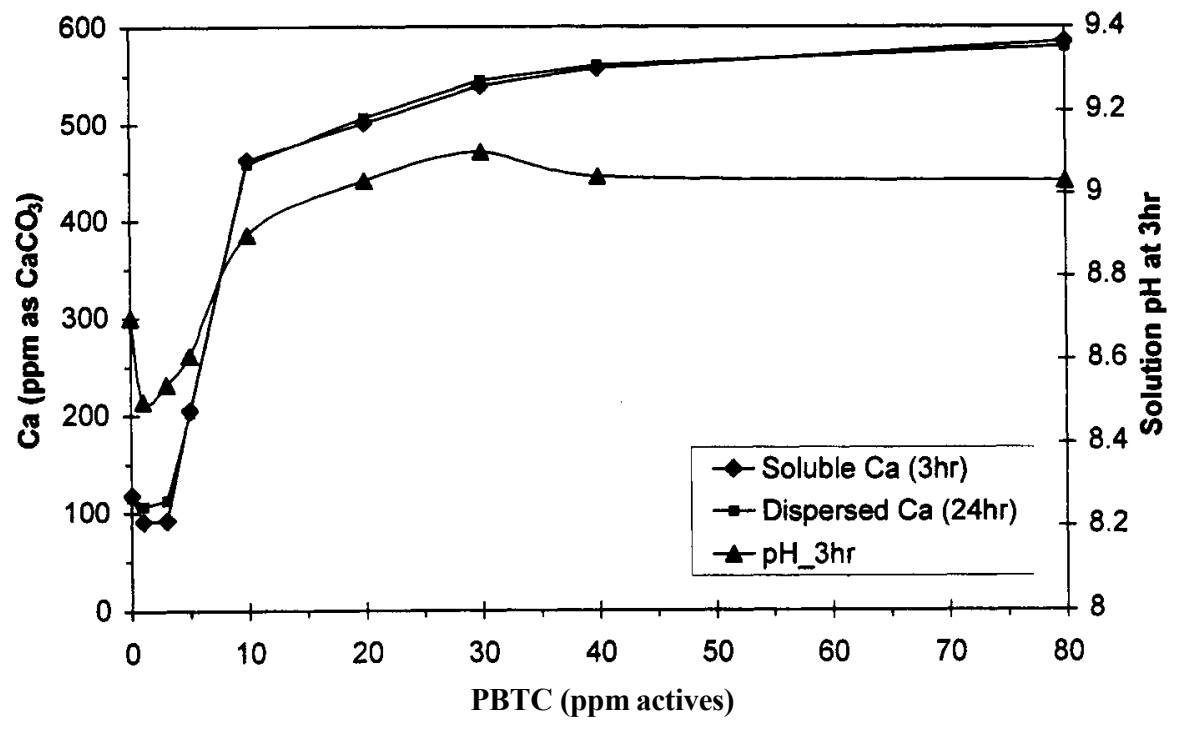

Figure 8. $\mathrm{CaCO}_{3}$ inhibition in the presence of various dosages of PBTC. Results were obtained with the aeration test. Conditions were: $800 \mathrm{Ca}, 200 \mathrm{Mg}, 800 \mathrm{NaHCO}_{3}$ (all in ppm as $\mathrm{CaCO}_{3}$ ), at $110^{\circ} \mathrm{F}$.

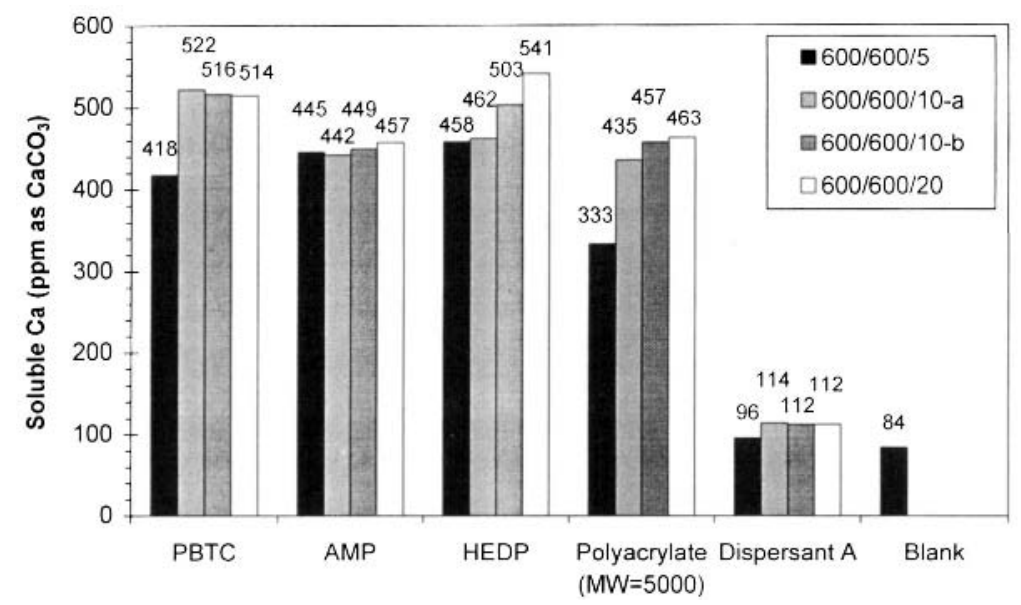

Figure 9. $\mathrm{CaCO}_{3}$ inhibition in the presence of various dosages of inhibitors. Conditions were: $600 \mathrm{Ca}, 200$ $\mathrm{Mg}, 600 \mathrm{NaHCO}_{3}$ (all in ppm as $\mathrm{CaCO}_{3}$ ), at $110{ }^{\circ} \mathrm{F}$. The second and third bars (a and b) are duplicate trials. 


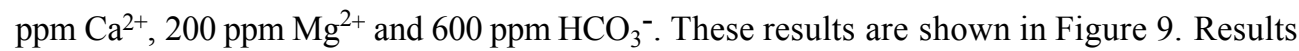
obtained at $10 \mathrm{ppm}$ inhibitor are duplicate tests. In general, the aeration test shows good reproducibility with error being $\pm 5-9 \%$.

Based on the results obtained under the test conditions, $\mathrm{CaCO}_{3}$ scale inhibition performance has the following sequence at $5 \mathrm{ppm}$ inhibitor actives.

$$
H E D P \sim A M P>P B T C>\text { Polyacrylate }>>\text { Dispersant } A \sim \text { blank }
$$

When the inhibitor concentration is increased to $10 \mathrm{ppm}$ the performance ranking is

$$
P B T C>H E D P \sim A M P>\text { Polyacrylate }>>\text { Dispersant } A
$$

Increasing inhibitor concentration to $20 \mathrm{ppm}$ seems to have little added effect.

Effect of Dispersant/Phosphonate Blends in $\mathrm{CaCO}_{3}$ Inhibition. The effect of Dispersant A on inhibitor performance was also studied with the aeration test. Inhibitors such as PBTC, HEDP, AMP, polyacrylate (MW = 5000) in concentrations 10 or $30 \mathrm{ppm}$ actives were added to solutions containing $800 \mathrm{ppm} \mathrm{Ca}^{2+}, 200 \mathrm{ppm} \mathrm{Mg}^{2+}$ and $800 \mathrm{ppm}$ $\mathrm{HCO}_{3}{ }^{-}$. Based on soluble $\mathrm{Ca}$ measurements with and without $10 \mathrm{ppm}$ Disperant $\mathrm{A}$, the inhibition performance sequence established at lower $\mathrm{Ca}$ and $\mathrm{M}$ alkalinity stress remains largely the same (except that at $10 \mathrm{ppm}$ polyacrylate performs better than $10 \mathrm{ppm}$ AMP). It appears that the presence of $10 \mathrm{ppm}$ Dispersant A improves the performance of $30 \mathrm{ppm}$ AMP and HEDP noticeably under the test conditions. Little or no effect was observed on PBTC and polyacrylate. This suggests that the less soluble inhibitors benefit more from the dispersant.

After 24 hours, the solutions were again tested (unfiltered) for Ca. These results give dispersed $\mathrm{Ca}$ and are presented in Figure 10. It is noticeable that Dispersant $\mathrm{A}$ has little effect on PBTC and polyacrylate. It again improves the performance of AMP and HEDP. We suggest that this is related to the ability of Dispersant A to disperse insoluble Ca-HEDP and Ca-AMP complexes that may form under the test conditions.

The effect of dispersant polymers on inhibition performance by blends of phosphonates was also studied by the aeration method. The water used contained $800 \mathrm{ppm} \mathrm{Ca}^{2+}, 200 \mathrm{ppm}$

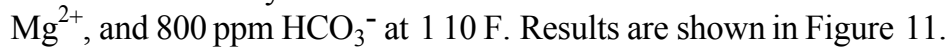

Dispersant A (15.5 ppm) seems to improve dispersed $\mathrm{Ca}$ in solutions containing 12 ppm PBTC and 8.4 ppm HEDP, over solutions containing Dispersant B. This effect is more pronounced compared to that of Dispersant C. It appears that different dispersant polymers impact $\mathrm{CaCO}_{3}$ scale inhibition performance in different ways. Dispersant $\mathrm{A}$ appears to be the most effective, whereas Dispersant $\mathrm{C}$ the least effective.

Pilot Cooling Tower Tests and Data Manipulation. PCT tests are very useful probes for studying in detail all cooling water dynamics in a unified fashion. There are several ways to "run" a PCT. In the present study, conductivity is increased incrementally, eventually reaching the point where calcium begins to precipitate out. The conductivity or the maximum calcium/alkalinity at this point indicate the limits of the treatment. The limit is lower at higher temperature. The limit is higher at higher inhibitor levels.

A total of 27 PCT tests were run. The variation of individual parameters was not varied according to a randomized factorial design. Fewer tests were run with polyacrylate, and different low molecular weight acrylate-based copolymers were used. More tests were run at the higher temperature. Several tests used identical formulations at different doses, contributing to a statistical correlation between the responses to the coefficients for the components in that formulation. Microbiological control was maintained with bleach, stabilized bleach, or stabilized bromine. 


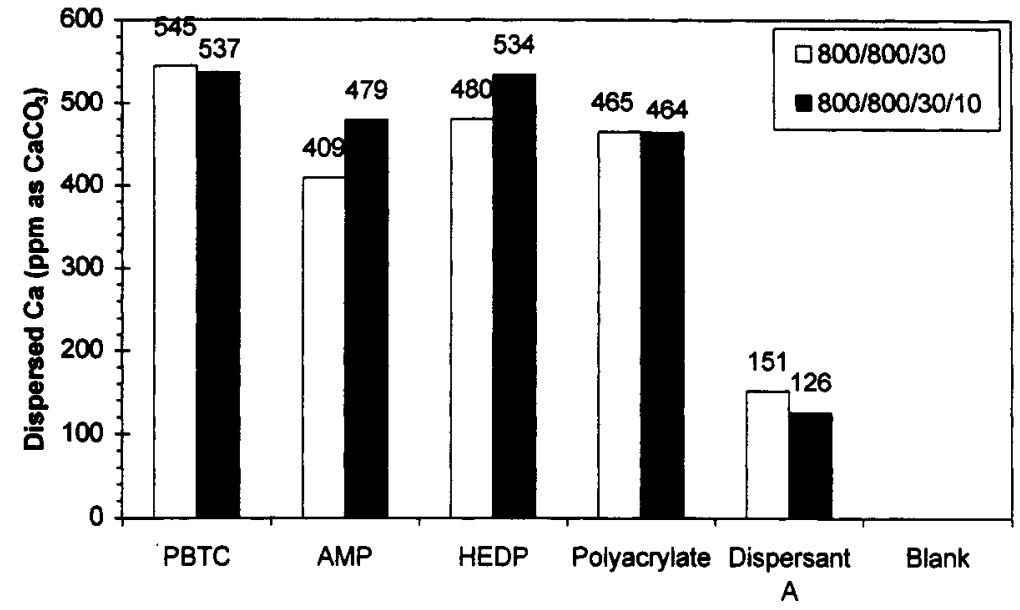

Figure 10. $\mathrm{CaCO}_{3}$ inhibition by PBTC, AMP and $\operatorname{HEDP}(30 \mathrm{ppm})$ in the absence and presence of Dispersant A (10 ppm). Conditions were: $800 \mathrm{Ca}, 200 \mathrm{Mg}, 800 \mathrm{NaHCO}_{3}$ (all in ppm as $\mathrm{CaCO}_{3}$ ), at $110^{\circ} \mathrm{F}$. Dispersed $\mathrm{Ca}$ measurements were done after $24 \mathrm{~h}$.

Some bench tests (eg., the $\mathrm{pH}$ static test described above) cannot differentiate between these inhibitors. They all reach a plateau of performance in the beaker tests. WaterCycle $\mathrm{e}^{\mathrm{TM}}$ from French Creek Software 38 was used to calculate the saturation ratios at the conditions of the conductivity limit.

Qualitatively, it is clear that lower inhibitor doses have lower limits. It is of great interest to determine a more quantitative description. In particular, individual component contributions to the overall performance would allow easy optimization of product formulations. Two attempts to extract this information from the PCT data will be described. Both gave very similar results.

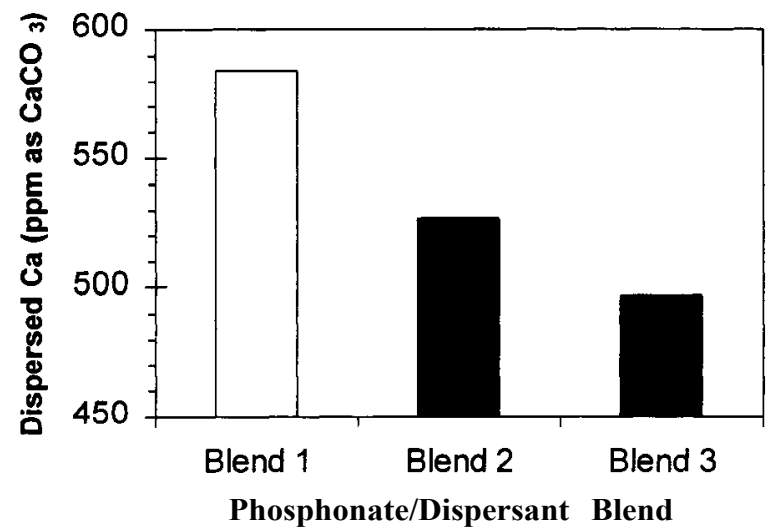

Figure 11. Synergistic effects between various phosphonates and Dispersants . Blend $1=12 \mathrm{ppm}$ PBTC +8.4 ppm HEDP + 15.5 ppm Dispersant A. Blend 2 $=12 \mathrm{ppm}$ PBTC + 8.4 ppm HEDP + 15.5 ppm Dispersant B. Blend $3=12 \mathrm{ppm}$ PBTC + $8.4 \mathrm{ppm}$ HEDP $+15.5 \mathrm{ppm}$ Dispersant C. Conditions were: $800 \mathrm{Ca}, 200 \mathrm{Mg}, 800$ $\mathrm{NaHCO}_{3}$ (all in ppm as $\mathrm{CaCO}_{3}$ ), at $110^{\circ} \mathrm{F}$. Dispersed Ca measurements were done after $24 \mathrm{~h}$. 
First, the maximum conductivity was determined (for each of 27 PCT tests) by graphically interpolating calcium and magnesium cycles as a function of conductivity. The "conductivity limit" is chosen to be where $\Delta$ Cycles (defined as MgCycles - CaCycles) first exceeds the value of 0.2 . Figure 12 gives one example.

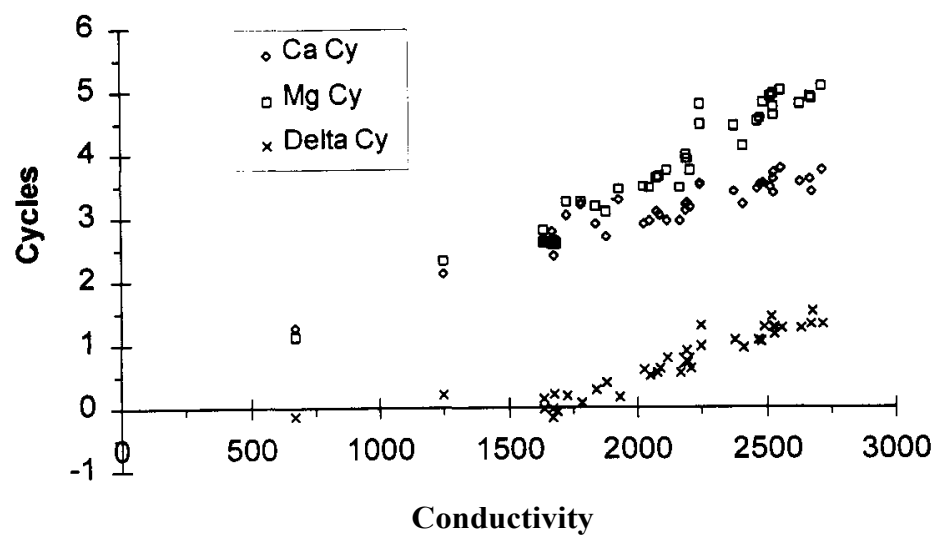

Figure 12. Effect of conductivity increase on $\mathrm{Ca}$ and $\mathrm{Mg}$ Cycles in a PCT test. The conductivity limit in this test is $\sim 1850(\mathrm{Cy}=$ Cycles $)$.

There was a clear tendency for tests at higher temperatures to perform worse. This was as expected based on the known solubility of $\mathrm{CaCO}_{3}$. Using WaterCycle ${ }^{\mathrm{TM}}$ software, it was shown that the saturation ratio (SR) for this water increases almost exactly $1 \%$ per 1 degree $\mathrm{F}\left(0.556{ }^{\circ} \mathrm{C}\right)$. SR also is proportional to concentration cycles squared (or alternatively, conductivity squared) in the region of interest. A number, denoted as Cond', proportional to SR but similar in magnitude to the conductivity was calculated as:

$$
\text { Cond' }=\frac{(\text { Conductivity })^{2} \times(\text { T Factor })}{2080}
$$

$$
\text { TFactor }=1+0.01 \mathrm{X}\left(\mathrm{T}_{\text {retum }}-80\right)
$$

Where 2080 is the average conductivity limit, and $\mathrm{T}_{\text {return, }}$, the temperature of the return water, is measured in degrees $\mathrm{F}$.

The resulting number for each test was fit (using JMP software) to a simple linear equation, where Cond' is equal to:

$$
\operatorname{Cond}_{0}+[a \cdot(\operatorname{ppm} \text { AMP })]+[h \cdot(\operatorname{ppm~HEDP~})]+[p \cdot(\operatorname{ppm~PBTC})]+[p a a \cdot(\operatorname{ppm} \text { PAA })]
$$

The parameters $a, h, p$ and are regression coefficients. In this treatment, for simplicity, paa refers to all the low molecular weigh acrylate-based copolymers. "Condo" was set at 1300 , which is the approximate conductivity value where precipitation occurs without any inhibitors added to the system. The results were: $a=39 \pm 13, h=76 \pm 21, p=51 \pm 14$, paa $=41 \pm 16$, Adj. $\mathrm{R}^{2}=0.60$.

For example, each ppm of AMP or PAA would be expected to raise the conductivity limit by about $40 \mu$ mhos. PBTC seems to be slightly better than AMP or polyacrylate, with 
HEDP even better, but the differences are not much larger than experimental variability. The trend seems to be real, but the fit is less than ideal. Attempting a logarithmic or square root fit of the dose response improved the fit very little (Adj. $\mathrm{R}^{2}=0.63$ ). The ratios of parameters for each inhibitor were similar to the ratios for those calculated above.

An alternate method was used to calculate the value of the "Ca $\times \mathrm{M}$ alkalinity" for each day of the test. This was observed to level off at each conductivity set point. This leveling off, where $\Delta$ Cycles was small, was taken as indicating the maximum attainable concentration under the test conditions. The daily analyses for those days were used to calculate the SR at that point for each test. SR values were between 60 and 120. The points selected by this method coincided well with the point of the conductivity limits described above for low conductivity limits / low doses / low SR. For higher conductivity / SR ratios there was a tendency for the maximum to occur at slightly higher conductivity than the conductivity limits. This may introduce a small systematic difference between the two methods.

A linear fit was poor (Adj. $\left.\mathrm{R}^{2}=0.45\right)$, but a logarithmic equation gave a good fit:

$\log (\mathrm{SR}-1)=$

Const $+n \cdot \log \{[a \cdot(\mathrm{ppm}$ AMP $)]+[h \cdot(\operatorname{ppm~HEDP~})]+[p \cdot(\operatorname{ppm} \mathrm{PBTC})]+[p a a \cdot(\mathrm{ppm} \mathrm{PAA})]\}$

Where "Const" was set equal to the log of the SR where precipitation is observed with no treatment, and $n=0.25, a=14.0 \pm 4.3, h=39.6 \pm 10.6, p=25.1 \pm 4.4$, paa $=9.8 \pm 13.3$, Adj. $\mathrm{R}^{2}=0.78$. Omitting the runs with polyacrylates (PAA) gave a similar fit, with $n=$ $0.25, a=13.6 \pm 4.5, \mathrm{~h}=41.7 \pm 12.1, p=25.0 \pm 4.6$, Adj. $\mathrm{R}^{2}=0.77$.

The value of $n$ greatly affects the values of the other parameters. Allowing $n$ to vary resulted in a value of 0.22 , which seemed unrealistically low. Fixing $n$ at 0.25 or 0.33 (fourth and cube roots of dosage) gave Adj. $\mathrm{R}^{2}$ values only slightly worse $(0.75$ and 0.73 respectively, compared to 0.78). For $n=0.5$ (square root of dose), the Adj. $\mathrm{R}^{2}$ was still 0.71. The values of the fitted parameters changed with $n$, but the relative rankings did not. HEDP remained the best, according to this treatment of the data, followed by PBTC and AMP and PAA. Lack of fit for tests with blends of phosphonates was indistinguishable from lack of fit for tests with single phosphonates. ${ }^{36,37}$ Thus, the fit of the data was surprisingly insensitive to the exponent of the inhibitor dose. The data in Figure 8 is consistent with a square root or fourth root of dose.

As a practical matter, the point is that the dose dependence of system performance is highly non-linear. Very high doses give only a little more inhibition than moderate doses. Money spent feeding excess product is largely wasted. However, slightly under-dosing the inhibitor can result in significantly higher deposit formation. This highlights the need for accurate control of product feed. ${ }^{17}$

\section{Inhibitor Stability Toward Oxidizing Biocides}

Although the primary criterion for potentially successful $\mathrm{CaCO}_{3}$ scale control is inhibition performance, secondary concerns are important as well. One of the most significant ones is inhibitor stability toward oxidizing biocides. One of the most common microbiological treatments is chlorine. Due to its strong oxidizing power, chlorine works effectively but, unfortunately, can degrade the scale inhibitors present in the water treatment program. As a result, chlorine-resistant technologies find widespread acceptance and popularity.

Inhibitor degradation by oxidizing biocides is undesirable for several reasons: (a) the system is depleted from inhibitor leading to poor scale control (b) orthophosphate is one of 
the by-products of decomposition of phosphorous-containing inhibitors and may lead to calcium phosphate scale (c) the oxidizing power of the biocide is "consumed" in decomposing the inhibitor and not to sterilize the system, which leads to (d) poor microbiological control. These problems can be minimized by use of halogen stabilizers or more halogen-resistant scale inhibitors, or an appropriate biocide-inhibitor combination.

It is well known that oxidizers attack treatment chemicals. ${ }^{39-42}$ The severity and importance of this depends on system conditions, type of oxidizer, and type of treatment chemical. Benchtop testing in the present study showed that degradation of inhibitors depends on factors such as $\mathrm{pH},\left[\mathrm{Ca}^{2+}\right]$, impurities, temperature, as well as the oxidizer itself.

The two biocides most often used to control microbial growth in HVAC cooling systems are chlorine and bromine. Ozone, iodine, and non-oxidizing biocides are used much less frequently. Chlorine is less expensive per mole of oxidant, but bromine, at $\mathrm{pH} 8$ - 9, is more effective for any given oxidant level. Hypobromous acid has a higher pKa than hypochlorous acid. ${ }^{40}$ This allows a higher percentage of the bromine biocide to be present in the more active acid form, while chlorine is predominantly in the less active ionized form.

While phosphonates are, in general, more prone to oxidation than carboxylates, it is an oversimplification to say that all phosphonates are unstable in the presence of oxidizers. Figure 13 shows that PBTC is very resistant to oxidation. HEDP is quite resistant to chlorine, but readily attacked by bromine. AMP on the other hand, is readily attacked by chlorine, but to a lesser extent by bromine. The bromine results are in excellent agreement with the results of Vanderpool et al., who used High Performance Liquid Chromatography (HPLC) to study the decomposition of various inhibitors by bromine. ${ }^{43}$ This indicates that when chlorine is used as the biocide in a system, AMP is not a good choice for a scale inhibitor because it is rapidly degraded by chlorine. PBTC or a (less expensive) PBTC/HEDP blend would be a good choice. Indeed, such programs have been used

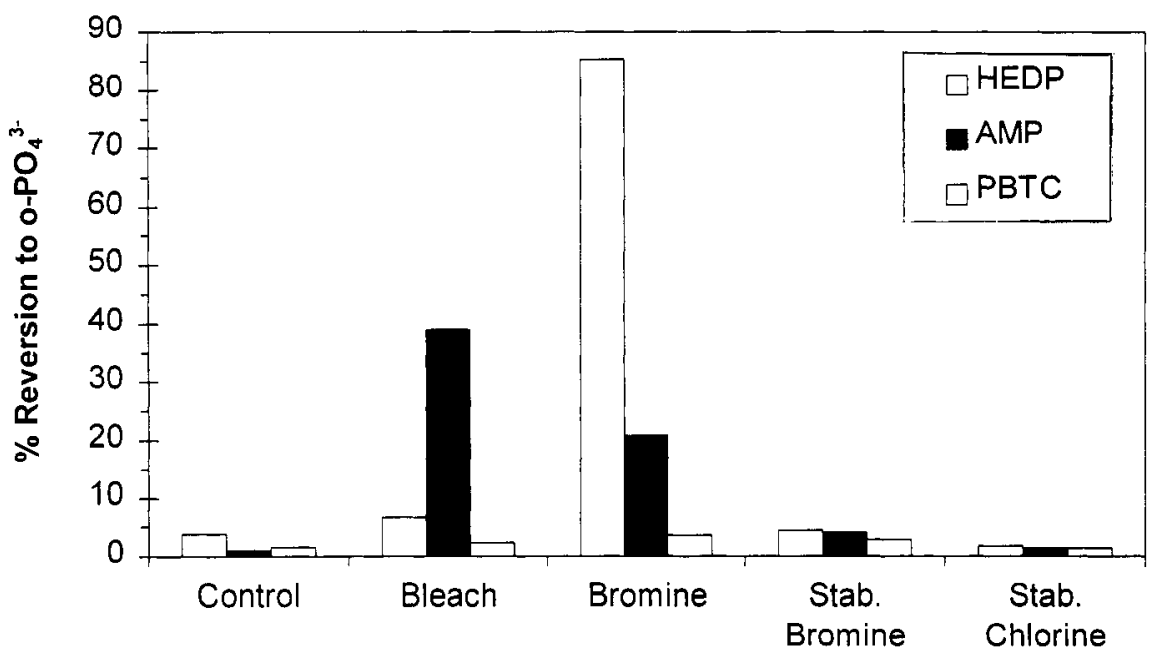

Figure 13. Effect of various oxidizing biocides on $\mathrm{CaCO}_{3}$ inhibitors. These data were obtained after one hour at $25{ }^{\circ} \mathrm{C}, \mathrm{pH} 8.3$, for solutions containing $5 \mathrm{ppm}$ phosphonate and $5 \mathrm{ppm}$ oxidizing biocide (as total $\mathrm{Cl}_{2}$ ) with the same makeup water as the PCTs. 
successfully for many years. With bromine as the biocide, PBTC or a PBTC/AMP blend would be the best choice.

In cooling towers a constant, low halogen residual is usually maintained. Therefore, it may seem that the "high-dosage" benchtop tests do not represent a practical situation. On the other hand, it is known that many operators "slug-feed" oxidizing biocides 1 - 3 times per week. In this case, high local concentrations of oxidizer may be experienced.

In a related study (unpublished results), a low oxidizer residual $(0.25 \mathrm{ppm})$ was maintained with an on-line chlorine analyzer in a small recirculating system. Degradation of HMDTMP (see Figure 3) was $\sim 1 \mathrm{ppm} /$ hour with chlorine, $\sim 0.4 \mathrm{ppm} /$ hour with bromine, and less than $0.03 \mathrm{ppm} /$ hour for the stabilized halogens.

In a PCT, phosphonate loss to oxidation can be estimated by calculating the difference between theoretical and measured organic phosphate. With PBTC and stabilized chlorine, there in no such degradation observed. With AMP or HEDP and stabilized bromine, the loss due to oxidation is discernable, but not large. An estimate of the relative reactivity of each phosphonate from the PCT data is in excellent agreement with benchtop data. It should be noted that the choice of oxidant does not affect either the program limit or the scaling rate.

There were several additional experiments in which oxidizing biocides were added to PCT's over a 10-20 minute period (slug-feed). Slugs of 2 - 4 ppm (as C12) had no detrimental effect on organophosphonate or $\mathrm{PO}_{4}{ }^{3-}$ (measured $16-40$ hours after the slug). They also had no effect on loss of Ca $\Delta$ Cycles), and on deposition (visual or Heat Transfer Resistance). The only time such effects were observed was during an upset of over $20 \mathrm{ppm}$ stabilized bromine (as total C12) for several days. HEDP decreased from 2.0 to $1.0 \mathrm{ppm}$, and $\mathrm{PO}_{4}{ }^{3-}$ increased from 0.2 to $1.0 \mathrm{ppm}$ during the same period. $\Delta$ Cycles increased from 0.6 to 1.0 , indicating increased $\mathrm{CaCO}_{3}$ precipitation.

The principal role of oxidizing biocides in cooling systems is to control microbial growth. However, they may adversely affect and degrade the scale inhibitors present in the water treatment program. Proper combinations of oxidizing biocides and scale inhibitors have to be chosen to ensure both microbial and scale control. Stabilized bromine, for example, is an effective biocide and does not degrade phosphonates, eg., HEDP, to any appreciable extent under common cooling tower operating conditions.

\section{CONCLUSIONS}

Cooling water accounts for most of the water used in industrial applications. Many cooling systems conserve water by operating under conditions of high mineral salt supersaturation, particularly $\mathrm{CaCO}_{3}$. Inhibitors, usually phosphonates or carboxylates, are required to prevent scale. However, simply measuring the ability of a molecule to inhibit calcite precipitation in a beaker is insufficient. Cooling water systems are complex and dynamic. They are affected by many factors not present in "beaker" tests. Individual systems are unique, and each is operated to achieve unique performance goals. Treatment programs must balance scale, corrosion, and microbial control for specific conditions. This paper described the effects of calcium and oxidizing biocides on scale inhibitors, as well as performance characteristics of those inhibitors.

Effective cooling water treatment is a complex and challenging process. It is a multifaceted task that requires control of three major factors: scale, microbiological growth and corrosion. Monitoring and feed control of the cooling water treatment program is also very important for the success of the application. This eliminates over/under-feeding of treatment chemicals and ensures better control by the cooling tower operator. 
The success of any water treatment program depends on its versatility, proper application and appropriate control of variables. Properly selecting and combining inhibitors and dispersants allows the water chemist to develop high-performing, costeffective formulations, which minimize both scale and corrosion at high cycles and with any biocide program. Inhibitors, either phosphonate or carboxylate, can be chosen for desired activity and sensitivity towards hardness and oxidizer.

\section{ACKNOWLEDGMENTS}

The authors wish to thank R. V. Davis, M. A. Kamrath, B. S. Bedford, F.-Y. Lu, D. P. Pruss, J. C. Krcma, A. M. Shiely, N.M. Rao, and S. A. Borchardt for producing and sharing experimental results, D. A. Johnson for useful discussions, and P. S. White (University of North Carolina at Chapel Hill, Department of Chemistry) for collecting the single crystal $\mathrm{X}$-ray data on Ca-AMP.

\section{REFERENCES}

1. Cowan, J.C.; Weintritt, D.J. Water-Formed Scale Deposits, Gulf Publishing Co. Houston, TX, 1976, p. 93.

2. Pilson, M.E.Q. An Introduction to the Chemistry of the Sea, Prentice Hall, Upper Saddle River, NJ, 1998, p. 123.

3. F.N. Kemmer, The Nalco Water Handbook, McGraw-Hill Company, New York (1988)

4. J. Katzel, Fundamentals of cooling towers, Plant Engineering April 27:32 (1989).

5. Power Special Report, Cooling towers, Power March:S-1 (1973).

6. E.C. Elliot, Cooling towers, Power December:S-1 (1985).

7. C.R. Branan, Rules of Thumbfor Chemical Engineers, Gulf Publishing Co. Houston, TX, 1994, p. 127.

8. Sarig, S.; Ginio, O. A mechanism for retarded precipitation based on the time evolution of particle size and relative number density, J. Phys. Chem. 80:256 (1976).

9. Koutsoukos, P.G.; Kontoyannis, C.G. Precipitation of calcium carbonate in aqueous solution, J. Chem. Soc. Faraday Trans.I 80:1 181 (1984).

10. Spanos, N.; Koutsoukos, P.G. Kinetics of precipitation of calcium carbonate in alkaline $\mathrm{pH}$ at constant supersaturation. Spontaneous and seeded growth, J. Phys. Chem. B 102:6679 (1998).

11. Oddo, J.E.; Tomson, M.B., Why scale forms and how to predict it, SPE Production \& Facilities February:47 (1994).

12. Johnson, C.K. ORTEP: A fortran thermal ellipsoid plot program; Technical Report ORNL-5138; Oak Ridge National Laboratory: Oak Ridge, T.N, 1976.

13. Gabe, E.J.; Le Page, Y.; Charland, J.-P.; Lee, F.L.; White, P.S., NRCVAX - an interactive program system for structure analysis, J. Appl. Crystallogr. 22:384 (1989).

14. International Tables for X-ray Crystallography; Kynoch Press: Bhigham, U.K., 1974; Vol. IV.

15. Reed, D.T.; Nass, R. Small-scale short-term methods of evaluating cooling tower treatments-are they worthwhile?, International Water Conference 1975, paper \# 1.

16. Fulks, K.E.; Yeoman, A.M., Performance evaluation of non-metal cooling water treatments, Corrosion/83, Paper No. 279, National Association of Corrosion Engineers, Houston, TX, 1983.

17. Hale, E.R.; Hoots, J.E.; Nicolich, S.N., Tracers track down water problems, Power Engineering September:21 (1999).

18. Reis, A.H. Jr.; Peterson, S.W.; Dryan, M.E.; Gebert, E.; Mason, G.W.; Peppard, D.F., Sterically hindered extractants. 2. A neutron-difiaction study of the di-tert-butylphosphinic acid dimer showing strong asymmetric hydrogen bonding, Inorg. Chem. 15:2748 (1976).

19. Smith, P.H.; Raymond, K.N., Solid-state and solution chemistry of calcium $N$ (phosphonomethyl)glycinate, Inorg. Chem. 27: 1056 (1988).

20. Langley, K.J.; Squattrito, P.J.; Adani, F.; Montoneri, E., Structures of fluorobenzylphosphonic acid isomers and their calcium salts, Inorg. Chim. Acta 253:77 (1996). 
21. DeLaMatter, D.; McCullough, J.J.; Calvo, C., Crystal structure of methylenediphosphonic acid, J. Phys. Chem. 77:1 146 (1973).

22. Gebert, E.; Reis, A.H. Jr.; Dryan, M.E.; Peterson, S.W.; Mason, G.W.; Peppard, D.F., Structural investigations of unsubstituted polymethylenediphosphonic acids 2 . The molecular and crystal structure of propane-1,3-diphosphonic acid, J. Phys. Chem. $81: 471$ (1977).

23. Uchtman, V.A.; Gloss, R.A., Structural investigations of calcium binding molecules. I. The crystal and molecular structures of HEDP.H2O, J. Phys. Chem. 76:1298 (1972).

24. Uchtman, V.A., Structural investigations of calcium binding molecules. II. The crystal and molecular structures of calcium-HEDP.2H2O; Implications for polynuclear complex formation, J. Phys. Chem. 76:1304 (1972).

25. Nardelli, M.; Pelizzi, G.; Staibano, G.; Zucchi, E., A structural study on metal binding of gemdiphosphonates, bonegrowth regulators, Inorg. Chim. Acta 80:259 (1983).

26. Mathew, M.; Fowler, B.O.; Breuer, E.; Golomb, G.; Alferiev, IS; Eidelman, N., Synthesis, characterization, and crystal structure of dicalcium glutarylbis(phosphonate) dihydrate: a covalently pillared layer structure with the potential for epitaxial growth on hydroxyapatite, Inorg. Chem. 37:5485 (1998).

27. Räsänen J.P.; Pohjala, E.; Nikander, H.; Pakkanen, T.A., Ab initio studies on organophosphorous compounds. 6. Interactions of dimethylphosphinic and dimethyl-phosphinothioic acid monoanions and methylenebisphosphonic acid dianion with calcium, J. Phys. Chem. A 101:5 196 (1997), and references therein.

28. Davis, R.V.; Carter, P.W.; Kamrath, M.A.; Johnson, D.A.; Reed, P.E. The use of modem methods in the development of calcium carbonate inhibitors for cooling water systems, in Mineral Scale Formation and Inhibition, Amjad, Z., ed., Plenum Press, New York (1995, p. 33.

29. Charpin, P.P.; Lance, M.; Nierlich, M.; Viper, D.; Lee, M.-R.; Silvestre, J.-P.; Dao, N.Q., Structure du Trihydrogéno hydroxy-1 -ethanedi(phosphonate)-1,1 de rubidium dihydrate, Acta Crystallog. Sect. C Cryst. Struct. Comm. C44:990 (1988).

30. Vanderpool, D., New calcium carbonate scale inhibitors: understanding complexation constants as a tool for finding improved performance, International Water Conference, paper \# 40, p. 383 (1997).

3 1. Carter, R.P.; Carrol, R.L.; Irani, R.R., Nitrilotris(methylenephosphonic acid), ethyliminodi(methylenephosphonic acid) and diethylaminomethylenephosphonic acid: acidity and calcium(II) and magnesium(II) complexing, Inorg. Chem. 6:939 (1967).

32. Deluchat, V.; Bollinger, J-C.; Serpaud, B.; Caullet, C., Divalent cations speciation with three phosphonate ligands in the $\mathrm{pH}$-range of natural waters, Talanta 44:397 (1997).

33. Oddo, J.E.; Tomson, M.B., The solubility and stoichiometry of calciumdiethylenetriaminepenta(methylene phosphonate) at $70^{\circ} \mathrm{C}$ in brine solutions at 4.7 and $5.0 \mathrm{pH}$, Applied Geochem. 5:527 (1990).

34. Sawada, K.; Araki, T.; Suzuki, T., Complex formation of amino polyphosphonates. 1. Potentiometric and nuclear magnetic resonance studies of nitrilotris(methylenephosphonato) complexes of the alkaline-earthmetal ions, Inorg. Chem. 26:1199 (1987).

35. Kabachnik, M.I.; Medved, T.Y.; Dyatlova, N.M. Rudomino, M.V. Russ. Chem. Rev. 1974,43,733.

36. Matty, J.M.; Tomson, M.B., Effect of multiple precipitation inhibitors on calcium carbonate scale nucleation, Appl. Geochem. 3549 (1988).

37. Tomson, M.B., Effect of precipitation inhibitors on calcium carbonate scale formation, J. Cryst. Growth 62:106 (1983).

38. Ferguson, R.J.; Freedman, A.J.; Fowler, G.; Kulik, A.J.; Robson, J.; Weintritt, D.J., The practical application of ion association model saturation indices to commercial water treatment problem solving, in Mineral Scale Formation and Inhibition, Amjad, Z., ed., Plenum Press, New York (1995), p. 323.

39. Johnson, D.A.; Fulks, K.E.; Meier, D.A., Factors influencing the decomposition of HEDP by chlorine, Corrosion/86, Paper No. 403, National Association of Corrosion Engineers, Houston, TX, 1986.

40. Bartholomew, R.D., Bromine-based biocides for cooling water systems: a literature review, International Water Conference, paper \# 74, p. 523 (1998).

41. Vaska, M.; Go, W., Microbial control. Evaluation of alternatives to gaseous chlorine for cooling water, Industrial Water Treatment March/April:39 (1993).

42. Brochures on "Dequest ${ }^{\text {}}$ Phosphonates" by Solutia.

43. Berg, D.; Vanderpool, D.; Rubin, D., Ion chromatographic analysis of organophosphonates in cooling water, International Water Conference, paper \# 7, p. 56 (1987). 